\title{
Avaliação das fibras colágenas de feridas dérmicas de coelhos tratadas com diferentes fontes de plasma rico em plaquetas
}

[Evaluation of collagen in dermal wounds of rabbits treated with different sources of platelet-rich plasma]

\author{
E. Ferraciolli ${ }^{1}$, C.B. Laposy ${ }^{2 *}$, M.R. Nogueira ${ }^{2}$, L.A. Justulin Júnior ${ }^{3}$, J.C. Camargo Filho ${ }^{4}$, \\ V. Moreira ${ }^{1}$, M.E. Marques ${ }^{1}$, G. Nai ${ }^{2}$, G. Ozaki ${ }^{4}$ \\ ${ }^{1}$ Pós-graduação - Universidade do Oeste Paulista - Presidente Prudente, SP \\ ${ }^{2}$ Universidade do Oeste Paulista - Presidente Prudente, SP \\ ${ }^{3}$ Universidade Estadual Paulista "Júlio de Mesquita Filho" - Botucatu, SP \\ ${ }^{4}$ Universidade Estadual Paulista “Júlio de Mesquita Filho” - Presidente Prudente, SP
}

\section{RESUMO}

Para comparar a regeneração tecidual de feridas dérmicas em coelhos tratados e não tratados, de forma seriada, com diferentes fontes de plasma rico em plaquetas (PRP) gel, biópsias dérmicas foram feitas na região dorsal, com auxílio de um punch de $8 \mathrm{~mm}$, em que o lado direito foi tratado com $\mathrm{NaCl} 0,9 \%{ }^{\circledR}$ e o lado esquerdo recebeu aplicação de diferentes fontes de PRPs (autóloga, heteróloga e homóloga), nos dias zero, três, sete, 10, 14, tendo sido acompanhadas durante 17 dias. Ao final do $17^{\circ}$ dia, foi realizada avaliação histopatológica das feridas. Do total de 24 animais, seis coelhos (três machos e três fêmeas) foram utilizados somente como doadores para obtenção do PRP homólogo gel. Um cão adulto, saudável, foi utilizado como doador durante o experimento para o preparo do PRP gel do grupo heterólogo. As médias das fibras dos grupos autólogo e homólogo foram muito semelhantes $(75,0 \pm 13,7$ e 73,1 110,2 , respectivamente), quando comparadas às médias obtidas no grupo controle $(71,5 \pm 10,8)$. Já as fibras colágenas do grupo heterólogo foram inferiores $(P<0,05)$ às dos demais grupos $(59,4 \pm 11,3)$. Conclui-se que a fonte heteróloga produz fibras colágenas menos organizadas e menos homogêneas, sendo o último recurso a ser utilizado para promover uma cicatrização de boa qualidade.

Palavras-chave: coelhos, feridas dérmicas, cicatrização, fibras colágenas, plasma rico em plaquetas

\begin{abstract}
In order to compare the tissue regeneration of dermal wounds in treated and untreated rabbits serially with different sources of platelet rich plasma (PRP) gel, dermal biopsies were made in the dorsal region with the aid of an $8 \mathrm{~mm}$ punch. The right side was treated with $0.9 \% \mathrm{NaCl}$ and, on the left side, the different sources of PRPs (autologous, heterologous and homologous) on days 0, 3, 7, 10, 14 were applied and monitored for 17 days. At the end of the 17th day, histopathological evaluation of the wounds was performed. From the total of 24 animals, six rabbits ( 3 males and 3 females) were used only as donors to obtain the homologous PRP gel. A healthy, adult dog was used as a donor during the experiment to prepare the PRP gel from the heterologous group. The mean values of the fibers of the autologous and homologous groups were very similar $(75.0 \pm 13.7$ and $73.1 \pm 10.2$, respectively), when compared to the means obtained in the control group (71.5 \pm 10.8$)$. The collagen fibers of the heterologous group were inferior $(P<0.05)$ to the other groups $(59.4 \pm 11.3)$. It is concluded that the heterologous source produces less organized and homogeneous collagen fibers and should be the last resource to be used in order to promote good quality healing.
\end{abstract}

Keywords: rabbits, dermal wound scaring, collagen fibers, platelet-rich plasma

Recebido em 10 de novembro de 2016

Aceito em 13 de novembro de 2017

*Autor para correspondência (corresponding author)

Email: claposy@unoeste.br 


\section{Ferraciolli et al.}

\section{INTRODUÇÃO}

Estudos experimentais sugerem novas opções terapêuticas para solucionar possíveis problemas no processo cicatricial. Atualmente o plasma rico em plaquetas (PRP) tornou-se uma opção de tratamento promissor e vem sendo utilizado em várias áreas da saúde, como na ortopedia, odontologia e cirurgia plástica (Monteiro, 2013).

Recentemente pesquisadores descreveram os benefícios do PRP para rejuvenescimento cutâneo. Na Itália, Readelli et al. (2010) utilizou o PRP para revitalização da face e do pescoço e obteve melhora da textura da pele e redução de pequenas rugas. Uma hipótese para este achado fo a provável estimulação da produção de ácido hialurônico, o que facilitaria a absorção de água e, consequentemente, promoveria maior firmeza, turgor e hidratação à pele, contribuindo, assim, para a formação das fibras de colágeno (Banihashemi e Nakhaeizadeh, 2014; Conde Monteiro et al., 2015).

Na estética, o uso do PRP tem contribuído com a biotecnologia por atuar como ferramenta e adiar o processo de envelhecimento cutâneo, sendo um processo seguro, tolerável e pouco invasivo (ELDomyati e Medhat, 2013; Santos et al., 2013).O biomaterial, quando injetado no tecido, aumenta a capacidade de regeneração tecidual por estimular os fatores de crescimento e ativar a angiogênese, e, por fim, induzir a síntese de colágeno por meio da estimulação dos fibroblastos (Ganceviciene et al., 2012; ElDomyati e Medhat, 2013; Conde Monteiro et al., 2015).

O PRP é o derivado do sangue que possui grande quantidade de plaquetas. Por meio de ativação, estas liberam fatores de crescimento (FC), entre os quais se destaca o fator de crescimento derivado de plaquetas (PDGF), que estimula a síntese de DNA, a quimiotaxia e a síntese de colágeno, para que ocorra a cicatrização das feridas e o reparo tecidual (Kim et al., 2011).

No entanto, há situações que podem inviabilizar a utilização do PRP autólogo gel, como queimaduras de grandes extensões em que o indivíduo não possui quantidade ou qualidade suficiente de pele. Nesses casos, consideram-se outras fontes de PRPs, como o heterólogo e o homólogo, sendo este um recurso alternativo
(Barrionuevo et al., 2015). A hipótese deste estudo baseia-se em que o uso de outras fontes de plasma rico em plaquetas possa contribuir positivamente na cicatrização tanto quanto a fonte autóloga.

Diante de poucos relatos de estudos sobre o uso de diferentes fontes de PRPs para avaliar o processo de cicatrização, objetivou-se averiguar se diferentes fontes de PRPs podem contribuir no processo de cicatrização em relação à quantidade e organização das fibras colágenas, evitando-se um processo cicatricial inadequado.

\section{MATERIAL E MÉTODOS}

O trabalho foi aprovado pela Comissão de Ética no Uso de Animais (Ceua), sob o protocolo número 2584, e todo o experimento foi realizado no Biotério de Experimentação Animal da instituição de origem.

Para o estudo, foram utilizados 24 coelhos (12 machos e 12 fêmeas) da raça Nova Zelândia, por

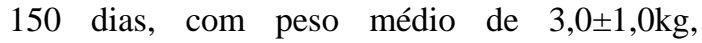
mantidos em gaiolas individuais, tratados com ração peletizada e água à vontade. Do total de 24 animais, seis coelhos (três machos e três fêmeas) foram utilizados somente como doadores para obtenção do PRP homólogo gel (PRPHo). Um cão adulto, saudável, sem raça definida, com peso médio de 25kg, foi utilizado como único doador durante o experimento para o preparo do PRP gel do grupo heterólogo (PRPHe). O animal passou por exames laboratoriais de rotina, que atestaram sua sanidade, e permaneceu, durante todo o período experimental, em uma baia individual no Hospital Veterinário da mesma instituição, recebendo ração e água à vontade. Foram utilizados seis coelhos (três machos e três fêmeas) para confecção do PRP do grupo autólogo gel (PRPA).

Os coelhos foram submetidos à tricotomia na região dorsal direita e esquerda, com máquina de tosa (Andis AGC2-USA), utilizando-se lâmina $\mathrm{n}^{0} .40$ para confecção das feridas cirúrgicas. Em seguida, foram anestesiados com cloridrato de tiletamina e zolazepan (Zoletil ${ }^{\circledR} 50,15 \mathrm{mg} / \mathrm{kg}$ IM,Virbac, Brasil), segundo protocolo de Kanashiro e Cassu (2008). Após anestesia, foi realizada antissepsia da pele com álcool 70\%, demarcação do local da lesão com uma caneta hidrográfica e aplicação de $0,5 \mathrm{~mL}$ subcutâneo de 
anestésico local (cloridrato de lidocaína a 2\% com vasoconstritor) em cada lado. As feridas foram realizadas com auxílio de um punch estéril de $8 \mathrm{~mm}$ de diâmetro, tanto na região do lado esquerdo (controle) como do direito (tratado) (Fig. 1).

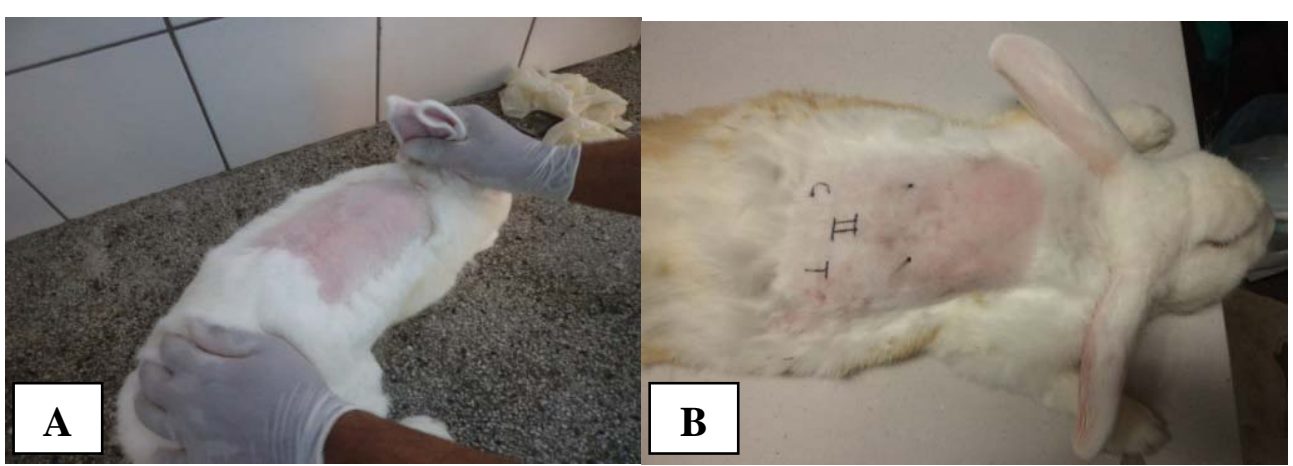

Figura 1.A - tricotomia da região dorsal. B - marcação para confecção das feridas.

Para o preparo dos PRPs autólogo e homólogo, retiraram-se $4,5 \mathrm{~mL}$ de sangue da veia auricular do próprio coelho e de cada coelho doador, respectivamente, utilizando-se Scalp 25G. Para cada coelho do grupo PRP heterólogo, coletaram-se $4,5 \mathrm{~mL}$ de sangue da veia jugular externa do cão adulto, hígido, sem raça definida, totalizando um volume final de sangue de 13,5mL/dia de aplicação. Os sangues (próprio coelho, cão e coelho doador) foram transferidos para frascos contendo anticoagulante citrato de sódio a 3,2\% (Santos et al., 2016) (BC Vacutainer, São Paulo, SP, Brasil).

Uma alíquota de material foi retirada de cada tubo para as contagens automática e manual de plaquetas (contador automático Sysmex Poch Diff 100iV - Roche Diagnóstica, São Paulo, SP, Brasil, e hemocitômetro, respectivamente). Em seguida, as amostras de sangue foram submetidas a uma primeira centrifugação (centrífuga Excelsa Baby 206R, Fanem ${ }^{\circledR}$, São Paulo, SP, Brasil) a 200 gravidades $(G)$ por 10 minutos, o que permitiu a formação de duas camadas: uma inferior, vermelha, com as hemácias, e outra superior, esbranquiçada, com plasma e plaquetas. Entre essas duas camadas, havia uma faixa fina e esbranquiçada, denominada zona de névoa, contendo leucócitos e plaquetas maiores.

Todo o plasma e $200 \mu \mathrm{L}$ da zona de névoa foram pipetados para um tubo seco e estéril e encaminhados para nova centrifugação (400G por 10 minutos). Além disso, foram transferidos mais $200 \mu \mathrm{L}$ da zona de névoa para um tubo seco e estéril. Após a segunda centrifugação, formaram-se dois níveis distintos: um superior, amarelo, e outro no fundo do tubo, vermelho, que correspondem, respectivamente, ao plasma pobre em plaquetas (PPP) e ao botão eritrocíticoplaquetário. O sobrenadante (PPP) foi descartado, e $200 \mu \mathrm{L}$ da parte correspondente ao botão eritrocítico-plaquetário foram transferidos para o tubo contendo a zona de névoa previamente separada. Em seguida, este tubo foi homogeneizado com $\mathrm{o}$ intuito de ocorrer a dispersão das plaquetas e a formação do PRP, totalizando $400 \mu \mathrm{L}$. Neste momento, realizou-se a contagem de plaquetas, tendo como referência mínima a quantidade de $1.000 .000 / \mathrm{mm}^{3}$ para ser considerado plasma enriquecido. No momento do tratamento da ferida, adicionou-se ao tubo o gluconato de cálcio a $10 \%$, na proporção de 4:1 (400 $\mu \mathrm{L}$ de PRP para $100 \mu \mathrm{L}$ de gluconato de cálcio) para a formação do gel. O volume final de PRP gel de todas as fontes foi de $0,5 \mathrm{~mL}$ (Oliveira-Filho et al., 2008).

Com as feridas prontas, o lado considerado controle (esquerdo) foi tratado com $\mathrm{NaCl}$ a $0,9 \%$, e no lado tratado foi inserido o respectivo gel (autólogo, heterólogo ou homólogo). Feito isso, ambas as feridas foram protegidas com rayon estéril e curativo adesivo (Band-Aid ${ }^{\circledR}$, Johnson \& Johnson do Brasil-Indústria e Comércio de Produtos para Saúde Ltda.). Após o procedimento cirúrgico, os animais receberam cloridrato de tramadol (0,5mg/kgIM, Teuto Brasileiro S/A-Anápolis-Goiás,Brasil), em um período de 12/12 horas, durante três dias consecutivos (Fig. 2). 


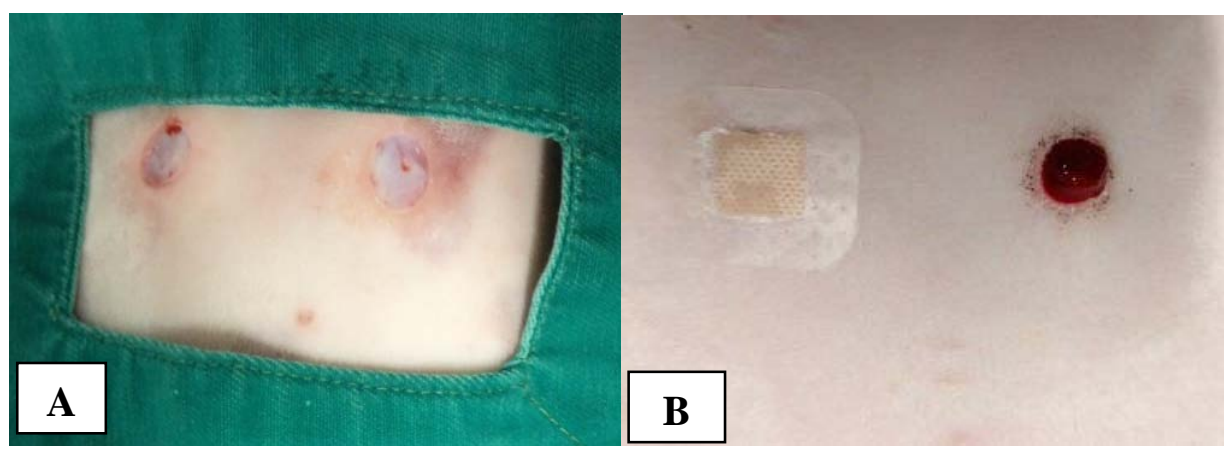

Figura 2.A - Feridas realizadas com punch 8mm. B - Lado esquerdo: ferida controle já tratada com $\mathrm{NaCl}$ a 0,9\%, e lado direito: colocação do PRPgel (seta).

A higienização (NaCL a 0,9\%) e a aplicação dos diferentes PRPs gel foram realizadas, de forma seriada, nos dias três, sete, 10 e 14 . Anteriormente a cada aplicação, foi realizada a mensuração em milímetros das bordas das feridas, com auxílio de um paquímetro digital (DC-60 Western ${ }^{\circledR}$, São Paulo, SP, Brasil). As medidas obtidas foram usadas para calcular o percentual da área remanescente de ferida em relação à área inicial (PAFR), utilizando-se a seguinte fórmula: $\mathrm{PAFR}=(\mathrm{AM} / \mathrm{AI}) \times 100 \%$, em que PAFR é o percentual da área de ferida em relação à área inicial, AI=área original da ferida no dia zero e AM=área mensurada em cada momento de avaliação. As feridas foram fotografadas em todos os dias de avaliação, empregando-se uma câmera digital (Nikon ${ }^{\circledR}$, Tóquio, Japão).

No $17^{\circ}$ dia, foi realizada a biópsia, com auxílio de um punch de $8 \mathrm{~mm}$ de diâmetro, abrangendo área central e borda das feridas para avaliação histológica e observação da fase inicial de remodelação (Vendramin et al., 2010).

O procedimento anestésico utilizado foi semelhante ao modelo adotado para indução das feridas. Após a retirada das amostras de pele, os fragmentos foram fixados em solução de formol tamponado a $10 \%$, por 24 horas, e, em seguida, incluídos em parafina. Cortes de $5 \mu \mathrm{m}$ de espessura foram corados com picrosirius-red F3BA, para identificação das fibras colágenas por análise morfológica (Lattouf et al., 2014). A análise histológica foi realizada pelo mesmo patologista, sem o conhecimento prévio das fontes de PRPs.

Para quantificar e avaliar o colágeno, foi utilizada a técnica de polarização com o corante picrosirius-red F3BA (Lattouf et al., 2014). A coloração com picrosirius permite uma análise quantitativa simples e sensível para medição de colágeno e proteínas contidas em cortes de tecido. Com essa técnica, é possível quantificar os colágenos maduro e imaturo. No sistema RGB (Red, Green, Blue), as fibras de colágeno maduro, tipo I, mais espessas e fortemente birrefringentes, aparecem em amarelo, laranja e vermelho; enquanto as fibras do colágeno imaturo, tipo III, mais finas, dispersas e fracamente birrefringentes, aparecem em verde. Por meio desse método, é possível quantificar a área ocupada por tipo de colágeno em cada campo predeterminado do corte histológico (Greca et al., 2009; Coleman, 2011).

Para a captação das imagens, utilizou-se microscópio da marca Leica DMLB 80, ligado a uma câmera DC 300 FX sob luz normal. As imagens foram obtidas com o analisador de imagem Leica Q-Win e analisadas por meio de um software (versão 3 para Windows para análise histológica). Foram, então, selecionados aleatoriamente três campos da área de cicatrização. As imagens foram capturadas com padronização de objetiva de aumento de 20 vezes, intensidade máxima de luz do microscópio e polarização em plano de $90^{\circ}$.

Os valores relativos ao percentual da área remanescente da ferida em relação à área inicial foram comparados entre grupos controle $\mathrm{e}$ tratado pelo teste $\mathrm{t}$ não pareado. $\mathrm{O}$ teste não paramétrico de Kruskal-Wallis foi usado para avaliar as diferenças das porcentagens de fibras colágenas entre as feridas tratadas e não tratadas de cada fonte de PRP. Já os testes de Bartlett e Tukey foram utilizados ao se compararem as fibras colágenas dos diferentes grupos de 
tratamento. Todas as análises foram conduzidas com auxílio do programa $\mathrm{R}$, considerando-se nível de significância de 5\%.

\section{RESULTADOS E DISCUSSÃO}

A concentração plaquetária média final dos coelhos foi de $1549,2 / \mathrm{mm}^{3} \pm 383,0$ e a do cão foi de $1330,0 / \mathrm{mm}^{3}$, o que evidencia um aumento aproximado de cinco vezes o valor inicial $\left(309,8 / \mathrm{mm}^{3} \pm 76,6\right.$ e $266,0 / \mathrm{mm}^{3}$, respectivamente) e corrobora o resultado de Del Carlo et al. (2009), os quais relataram que, para que haja um efeito terapêutico, a concentração plaquetária deve estar acima de $1000,0 / \mathrm{mm}^{3}$. Na presente pesquisa, o protocolo de centrifugação foi adequado para obtenção de PRP de boa qualidade, semelhante ao descrito por Vendramin et al. (2009).

Com relação às diferentes fontes de PRP, o PRPHo gel mostrou-se tão eficiente quanto a fonte de PRPA gel em comparação à cicatrização, organização e quantidade de fibras colágenas. Macroscopicamente, o uso de PRP heterólogo gel proporcionou um fechamento da ferida tão bom quanto aqueles proporcionados pelos grupos autólogo e homólogo gel (Fig. 3). Como o PRP é rico em fatores de crescimento, ainda que estes sejam de outros animais da mesma espécie e também de espécies diferentes, vale ressaltar que, mesmo quando aplicados de forma seriada, os diferentes tipos de PRPs não ocasionaram efeito negativo, por exemplo, rejeição.

Barrionuevo et al. (2015), ao compararem o efeito do uso de diferentes fontes de PRPs (autólogo, heterólogo e homólogo) gel sobre o processo de cicatrização de feridas cutâneas, concluíram que, independentemente da fonte, seu uso melhora e acelera o processo de cicatrização. No presente estudo, verificou-se que as fontes autóloga e homóloga produziram uma fibra mais densa e homogênea, mas não houve uma aceleração da cicatrização.

A partir do $14^{0}$ dia pós-lesão, as áreas remanescentes das feridas diminuíram em todos os grupos (Tab. 1), mas especialmente nos lados tratados com as diferentes fontes de PRP. Os achados do presente estudo sugerem que a migração celular e a diferenciação dos miofibroblastos ocorreram de forma similar em todos os protocolos. Kane et al. (2015) utilizaram a fonte autóloga de PRP pós-implante de prótese de tornozelo e verificaram ausência de diferença entre grupos para promover a aceleração da cicatrização. Em contraste com esses resultados, Ostvar et al. (2015) observaram que feridas tratadas com PRP autólogo tiveram uma redução significativamente mais rápida da lesão, quando comparadas ao controle.

Tabela 1. Valores médios e desvios-padrão do percentual das áreas remanescentes das feridas ( $\mathrm{A}=$ controle), ( $\mathrm{B}=$ tratada) de coelhos tratados com plasma rico em plaquetas (PRPs) autólogo, heterólogo e homólogo, em diferentes dias

\begin{tabular}{|c|c|c|c|c|c|c|}
\hline & \multicolumn{6}{|c|}{ Fontes de PRps } \\
\hline & \multicolumn{2}{|c|}{ Autólogo } & \multicolumn{2}{|c|}{ Heterólogo } & \multicolumn{2}{|c|}{ Homólogo } \\
\hline Dias & A & B & $\mathrm{A}$ & B & A & B \\
\hline 3 & $90,7 \pm 17,4$ & $85,9 \pm 13,3$ & $81,7 \pm 14,0$ & $76,1 \pm 13,1$ & $86,8 \pm 25,6$ & $92,1 \pm 44,2$ \\
\hline 7 & $94,1 \pm 26,9$ & $74,7 \pm 10,4$ & $72,9 \pm 19,2$ & $61,4 \pm 13,8$ & $70,6 \pm 26,0$ & $75,7 \pm 37,1$ \\
\hline 10 & $82,8 \pm 33,4$ & $52,4 \pm 25,7$ & $58,5 \pm 28,9$ & $48,9 \pm 10,9$ & $51,0 \pm 9,2$ & $51,9 \pm 34,2$ \\
\hline 14 & $42,3 \pm 43,6$ & $28,4 \pm 23,4$ & $19,3 \pm 28,6$ & $15,6 \pm 12,2$ & $13,7 \pm 11,1$ & $12,3 \pm 12,7$ \\
\hline 17 & $9,7 \pm 6,7$ & $4,1 \pm 2,9$ & $3,5 \pm 7,9$ & $3,2 \pm 4,7$ & $2,2 \pm 2,4$ & $0,3 \pm 0,6$ \\
\hline
\end{tabular}

O lado tratado com os PRPs autólogo e homólogo sobressaiu-se em relação à organização das fibras colágenas quando comparado ao lado controle e ao grupo heterólogo (Fig. 3). Pazzini et al. (2016) obtiveram maior proliferação de fibroblastos e colagenização $(\mathrm{P}>0,05)$ ao usarem o $\quad \mathrm{PRP}$ autólogo em cirurgia reconstrutiva de padrão axial toracodorsal em coelhos. Seu estudo revelou ainda que a utilização do PRP foi capaz de estimular a angiogênese e de contribuir para promover e favorecer o processo de cicatrização, por aumentar a formação de novos vasos de pequeno e médio calibres, aumentando a vascularização e reduzindo os índices de necrose. No presente experimento, não foi verificada necrose tecidual na aplicação de diferentes fontes de PRP. Moreira (2016), ao estudar as fibras 
colágenas de coelhos tratados com PRP autólogo gel, verificou também um aumento na angiogênese das feridas tratadas quando comparadas às do grupo controle. Ganceviciene (2012) verificou que, quando injetado, o PRP promoveu aumento da regeneração tecidual por secreção de fatores de crescimento que estimulam uma melhora na vascularização tecidual, na angiogênese e na indução da síntese de colágeno, por meio da estimulação dos fibroblastos.
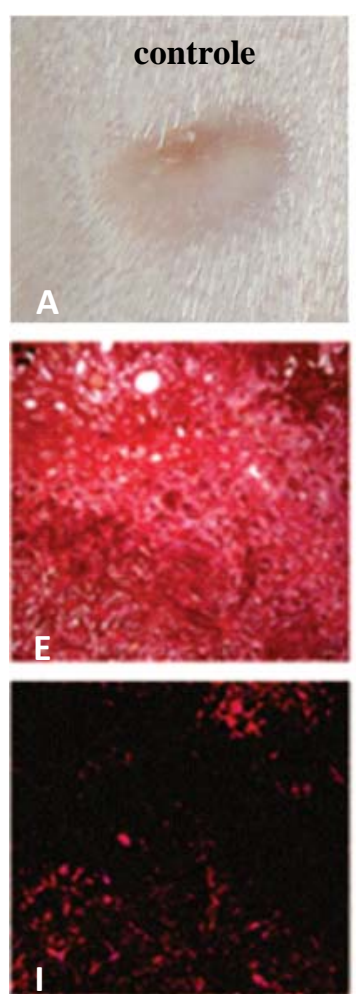
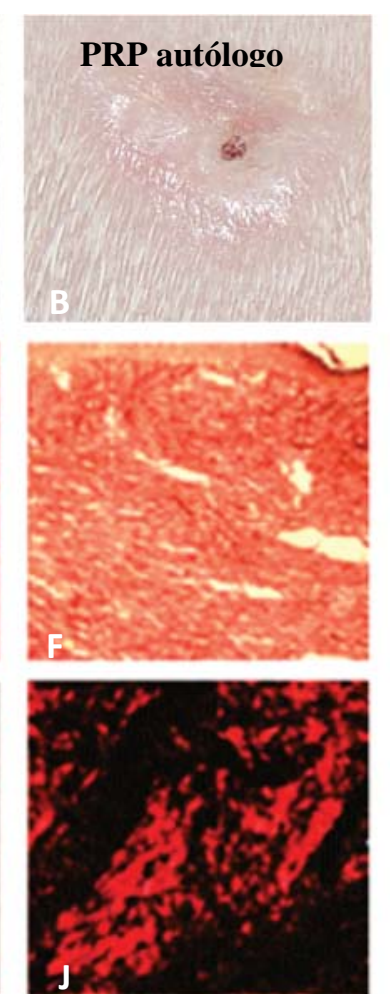
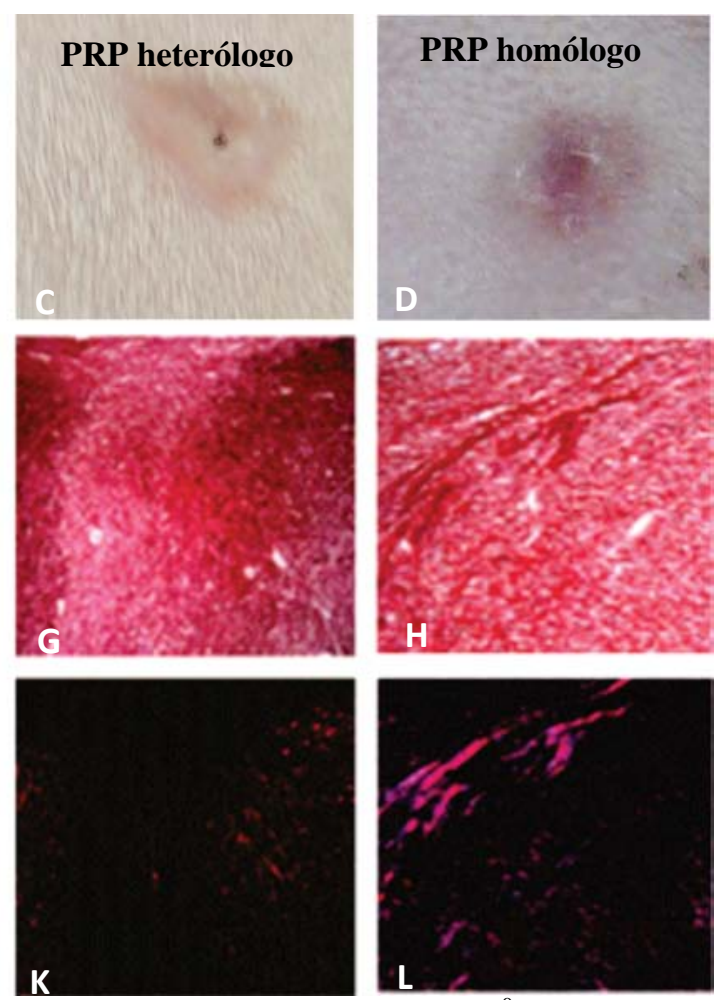

Figura 3. Fotografia mostrando o aspecto macroscópico das lesões ao final do $17^{0}$ dia dos grupos controle, PRPA, PRPHe e PRPHo gel, respectivamente, representados pelas letras A, B, C e D. Coloração com picrosirius (aumento 200x): E- (controle); F- (PRPA); G- (PRPHe); H- (PRPHo). Observou-se menor vascularização, maior organização e maior homogeneidade das fibras colágenas em relação ao PRP heterólogo (G). Avaliação da coloração com picrosirius à luz polarizada (aumento de 200x): I-( controle); J- (PRPA); K- (PRPHe); L - (PRPHo). Nota-se a birrefringência do colágeno, que evidencia a formação e a organização das fibras colágenas quando comparadas às do grupo controle.

Na Fig.4, foi possível observar que as médias das fibras de colágeno das fontes autóloga e homóloga gel foram semelhantes às do grupo controle, e a média da fonte heteróloga foi inferior às outras três do grupo tratado $(\mathrm{P}>0,05)$. Quarteiro et al. (2015), em seu estudo com ratos tratados com PRP homólogo gel no reparo de lesões musculares, descreveram que, na primeira avaliação feita aos sete dias, a quantidade média de colágeno foi significantemente menor nas lesões tratadas com PRP em relação às lesões controle, o que sugere uma possível redução do período do processo inflamatório ou alteração da liberação de citocinas. Observação semelhante foi verificada no presente estudo, em que os grupos tratados com fontes de PRPs autóloga e homóloga apresentaram menor quantidade de fibras colágenas quando comparados ao grupo controle, porém estas se mostraram mais organizadas e homogêneas. Marques et al. (2017), ao quantificarem o colágeno em feridas dérmicas de coelhos tratadas com PRPHe, concluíram que o uso desta fonte é capaz de induzir a produção de colágeno, sem aumentar sua quantidade ou acelerar o processo de cicatrização. Além disso, os autores alertam que seu uso deve ser uma alternativa somente quando não houver disponibilidade das fontes autóloga 
ou homóloga. Decalzi et al. (2013) justificaram o emprego do PRP ao verificarem que, sob condições inflamatórias, o biomaterial pode aumentar a produção de componentes relacionados ao sistema endocanabinoide, ao elevar significativamente seus mediadores e, consequentemente, produzir maior efeito analgésico no local da lesão, o que não é observado quando a ferida é tratada apenas com solução fisiológica.

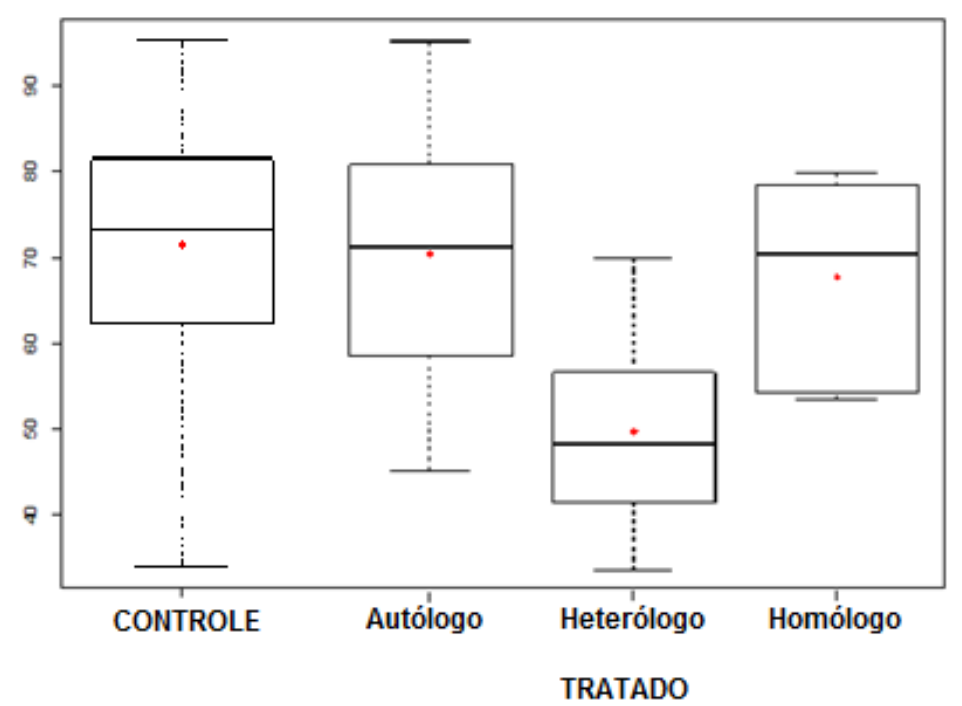

Figura 4. Porcentagem de formação das fibras colágenas dos grupos controle e tratados com diferentes fontes de PRPs gel. As linhas do interior dos boxes denotam 50\% dos dados - mediana; as linhas superiores, $75 \%$ dos dados; e as inferiores, $25 \%$ dos dados. As linhas externas ao boxe indicam os limites máximos e mínimos após o $17^{\circ}$ dia.

\section{CONCLUSÕES}

Conclui-se que as fontes de plasma rico em plaquetas autóloga e homóloga, quando aplicadas de forma seriada, são alternativas seguras e capazes de produzir fibras colágenas organizadas e homogêneas, o que favorece o processo cicatricial. A fonte heteróloga, apesar de produzir colágeno, deverá ser o último recurso utilizado para promover uma cicatrização de boa qualidade.

\section{REFERÊNCIAS}

BANIHASHEMI, M.; NAKHAEIZADEH, S. An introduction to application of platelet rich plasma (PRP) in skin rejuvenation. Rev. Clin. Med., v.1, p.38-43, 2014.

BARRIONUEVO, D.V.; LAPOSY, C.B.; ABEGÃO, K.G. et al. Comparison of experimentally-induced wounds in rabbits treated with different sources of platelet-rich plasma. Lab. Anim., v.49, p.209-214, 2015.
COLEMAN, R. Picrosirius red staining revisited. Acta Histochem., v.113, p.231-233, 2011.

CONDE MONTERO, E.; FERNÁNDEZ SANTOS, M.E.; SUÁREZ FERNÁNDEZ, R. Platelet-rich plasma: applications in dermatology. Actas Dermoifiliogr., v.106, p.104111, 2015.

DECALZI, F.; ULIVI, V.; CANCEDDA, R. et al. Platelet-rich plasma exerts antinociceptive activity by a peripheral endocannabinoide-related mechanism. Tissue Eng., part A, v.19, p.21202129, 2013.

DEL CARLO, R.J.; MONTEIRO, B.S.; SILVA, P.S.A. et al. Aspectos microscópicos da reparação mediada por plasma rico em plaquetas e autoenxerto esponjoso em falhas ósseas experimentais no crânio de coelhos. Vet. Zootec., v.16, p.152-160, 2009.

EL-DOMYATI, M.; MEDHAT, W. Minimally invasive facial rejuvenation current concepts and future expectations. Expert Rev. Dermatol., v.8, p.565-580, 2013. 


\section{Ferraciolli et al.}

GANCEVICIENE, R.; LIAKOU, A.I.; THEODORIDIS, A.; MAKRANTONAKI, E. Skin anti-aging strategies. Dermato-Endocrinol., v.4, p.308-319, 2012.

GRECA, F.H.; RAMOS, E.J.B.; DALLOLMO, V.C. et al. The clinical use of platelet-rich plasma in the promotion of bone healing: a systematic review. Injury, v.40, p.158-162, 2009.

KANASHIRO, G.P.; CASSU, R.N. Anestesia em animais selvagens e de laboratório. In: ANDRADE, S.F. Manual de terapêutica veterinária. São Paulo: Roca, 2008. p.728-745.

KANE, J.M.; COSTANZO, J.A.; RAIKIN, S.M. The efficacy of platelet-rich plasma for incisional healing after total ankle replacement using the agility total ankle replacement system. Foot Ankle Int., v.1, p.1-6, 2015.

KIM, D.H.; JE, Y.J.; KIM, C.D. et al. Can Platelet-rich plasma be used for skin rejuvenation? Evaluation of effects of Plateletrich plasma on human dermal fibroblast. Ann. Dermatol., v.23, p.424-431, 2011.

LATTOUF, R.; YOUNES, R.; LUTOMSKI, D. et al. Picrosirius red staining a useful tool to appraise collagen networks in normal and pathological tissues. J. Histochem. Cytochem., v.62, p.751-758, 2014.

MARQUES, M.E.M.; LAPOSY, C.B.; SILVA, M.L.S. et al. Collagen quantification in rabbit dermal wounds treated with heterologous platelet-rich plasma gel. Semin. Ciênc. Agrár., v.38, p.249-258, 2017.

MONTEIRO, M.R. Platelet-rich plasma in dermatology. Surg. Cosmet. Dermatol., v.5, p.155-159, 2013.

MOREIRA, V.C. Análise do colágeno e angiogênese de feridas dérmicas de coelhos tratados com PRP autólogo gel. 2016. 27f. Dissertação (Mestrado em Ciência Animal) Universidade do Oeste Paulista, Presidente Prudente, SP.
OLIVEIRA-FILHO, M.A.; ALMEIDA, L.E.; PEREIRA, J.A. et al. Plasma rico em plaquetas de coelhos: introdução a um modelo experimental. Arq. Bras. Cir. Dig., v.21, p.175179, 2008.

OSTVAR, O.; SHADVAR, S.; YAHAGHI, E. et al. Effect of platelet-rich plasma on the healing of cutaneous defects exposed to acute to chronic wounds: a clinic-histopathologic study in rabbits. Diag. Pathol., v.10, p.1-6, 2015.

PAZZINI, J.M.; NARDI, A.B.; HUPPES, R.R. et al. Utilização de plasma rico em plaquetas para estimulação da angiogênese em flape de padrão axial toracodorsal em coelhos (Oryctolagus ciniculus). Pesqui. Vet. Bras., v.36, p.108-118, 2016.

QUARTEIRO, M.L.; TOGNINI, J.R.F.; OLIVEIRA, E.L.F.; SILVEIRA I. O efeito do plasma rico em plaquetas no reparo de lesões musculares em ratos. Rev. Bras. Ortop., v.50, p.586-595, 2015.

READELLI, A.; ROMANO, D.; MARCIANO, A. Face and neck revitalization with Platelet-rich plasma (PRP): clinical outcome in a series of 23 consecutively treated patients. J. Drugs Dermatol., v.9, p.466-472, 2010.

SANTOS, E.Z.; LAPOSY, C.B.; ABEGÃO, K.G.B. et al. Assessment of the healing of standardized wounds in rabbits treated serially with autologous platelet-rich plasma gel. Semin. Ciênc. Agrár., v.37, p.4131-4138, 2016.

SANTOS, L.A.; ZOBOLI, F.; CORREIA, E.S. Estética/beleza e antienvelhecimento feminino: biotecnologia e potencialização do corpo. Praxia, v.1, p.48-61, 2013.

VENDRAMIN, F.S.; FRANCO D.; FRANCO T.R. Use of autologous platelet-rich plasma in skin grafts surgeries in chronic wounds. Rev. Bras. Cir. Plást., v.25, p.589-594, 2010.

VENDRAMIN, F.S.; FRANCO, D.; FRANCO, T.R. Método de obtenção do gel de plasma rico em plaquetas autólogo. Rev. Bras. Cir. Plást., v.24, p.212-218, 2009. 